\title{
The Effect of Mobile Learning on Students' Achievement and Conversational Skills
}

\author{
Abdellah Ibrahim Mohammed Elfeky ${ }^{1} \&$ Thouqan Saleem Yakoub Masadeh ${ }^{2}$ \\ ${ }^{1}$ Faculty of Specific Education, Kafrelsheikh University, Egypt \\ ${ }^{2}$ Department of Curriculum and Instruction, College of Education, Najran University, KSA \\ Correspondence: Dr. Abdellah Ibrahim Mohammed Elfeky, Kafrelsheikh University, Egypt.
}

Received: April 27, 2016

Accepted: May 16, 2016

Online Published: May 24, 2016

doi:10.5430/ijhe.v5n3p20

URL: http://dx.doi.org/10.5430/ijhe.v5n3p20

\begin{abstract}
The present study aimed to examine the effect of Mobile Learning, which is a kind of E- learning that uses mobile devices, on the development of the academic achievement and conversational skills of English language specialty students at Najran University. The study used the quasi-experimental approach. Participants consisted of (50) students who were registered in a course called "Strategies of Teaching and Learning" offered by the Department of Curriculum and Instruction at the College of Education to students majoring in English at the Department of English Language at the College of Science and Arts. As usual participant students were divided into experimental and control groups of (25) students in each. The soft copy of the course content was uploaded to the University Blackboard System for students in the experimental group. Another hardcopy of the course content was delivered to students in the control group by hand in the first meeting. Data collection tools included an academic achievement test and conversational skills rating scale. Results showed that mobile learning had quite significant effect on both students' academic achievement and conversational skills. In light of these findings faculty members were recommended to adapt the use of Mobile Learning in their classes.
\end{abstract}

Keywords: Mobile learning, Academic achievement, Conversational skills, Face-to-face learning

\section{Introduction}

Mobile Learning is a term that has been used widely in different places all over the world. In Saudi Arabia, for instance it has been encouraged to be used in higher education institutions because of a set of factors such as the availability of mobile phones, their ability to motivate students, and the freedom and privacy they provide to share information. Mobile Learning is defined as E-learning that uses mobile devices or learning connected to a mobile device, Laouris \& Eteokleous (2005). It is mainly based on mobility of technology, mobility of learners and mobility of learning that augments the higher educational landscape, (El-Hussein \& Cronje 2010). Educational institutions are nowadays facing the reality of the rapid development and widespread of mobile phones, which are considered one form of those mobile devices used for E-learning all over the world. Such development has involved an increase in both mobile phones speed and storage capacity. The continuous drop in prices, on the other hand has resulted in the vast widespread of these mobile phones making them one main component of most learners' (boys and girls) daily lives. Mobile phones are not accessory anymore; they are integrated like our clothes, (Dos 2014). It is true that mobile phones are mainly used for completely communication purposes, but fortunately, some people have begun to regard them as a core pedagogical activity in higher educational institutions, (El-Hussein \& Cronje 2010). The number of those teachers and students who have begun to use them as a teaching and/or learning tool is growing tremendously. Most students have started overcoming their difficulties regarding the place and time of lectures via the effective exploitation of their mobile phones or what has been so called "Mobile Learning". Teachers, on their turn have started to think seriously of providing their students with the teaching materials and activities through their mobile phones. Nowadays, Mobile Learning has been widely accepted by learners. In other words, learning via mobile devices is widely accepted by the learner community because of its application as well as its philosophy and standards, (Lan \& Huang, 2012 \& Little, 2012).

On the other hand, the teaching- learning materials should be re-designed, developed, and carried out in a way that fits this new kind of learning and makes it more effective. The advances in technology used in today's mobile phones qualify them to be instructional as well as communicational tools. In addition to their main purpose, mobile phones, 
are nowadays used to send and receive instructional messages through text, voice or even images, (Kim, et. al., 2013). Furthermore, mobile phones and consequently Mobile Learning facilitate accessing various educational resources on Internet and help developing and creating interesting teaching content that can be used inside or outside classrooms, (UNISCO, 2013). Mobile Learning can deliver the right information to the right person at the right time better than any other learning/teaching technology yet devised, (Little, 2012). Besides, students' interest to use all available resources of Mobile Learning through their mobile phones and Personal Digital Assistants (PDAs) to access information anytime and anywhere has also played a significant role in the success of mobile learning prevalence, (López, et. al. 2009). Mobile Learning not only fosters the way we access information, but also helps learners be innovative and good problem-solvers, (West, 2013).

Therefore, the present study, taking into account these preliminary considerations of mobile learning merits, has set an aim to determine the effect size in English language students' academic achievement and conversational skills that can be due to the use of either Mobile Learning or Face-to-Face learning. It also aims to determine which of these two learning ways is more effective and to what extent.

\subsection{Questions of the Study}

The present study aims to answer the following questions:

1. Is there any statistically significant difference between the effect of Mobile Learning in comparison with Face-to-Face learning on the academic achievement of English Language students' enrolled in "Strategies of Teaching and Learning" course at Najran University?

2. Is there any statistically significant difference between the effect of Mobile Learning in comparison with Face-to-Face learning on the development of the conversational skills of English Language students enrolled in "Strategies of Teaching and Learning" course at Najran University?

\subsection{Mobile Learning and E-learning}

Mobile Learning is a powerful method for engaging learners on their own terms and enhances their broader learning experience because of its mobility quality and supporting platform. It is considered merely an extension of Elearning combined to mobile computing. Users of Mobile Learning should be aware of mobile devices' benefits and specific limitations when delivering mobile learning quality, (Behera, 2013:65). The evolution of E-learning, as a new form of distance learning whose terminology is close to those of traditional learning, has encouraged the varied applications of Mobile Learning. Nevertheless, Mobile Learning is a characterized technology and has its own terminology that adopts terms like spontaneous, intimate, situated, connected, informal, and lightweight, while Elearning uses different terms such as multimedia, interactive, hyperlinked, and media-rich environment, (Korucu \& Alkan, 2011:1926-7). Laouris \& Eteokleous (2005) have presented table (1) below to contrast between the terminologies of both terms.

Table 1. Terminology contrast between E- and mobile-learning

\begin{tabular}{cc}
\hline \multicolumn{2}{c}{ Dominant terms by: } \\
\hline E- Learning & Mobile Learning \\
\hline Computer & Mobile \\
Bandwidth & GPRS, G3, Bluetooth \\
Multimedia & Objects \\
Interactive & Spontaneous \\
Hyperlinked & Connected \\
Collaborative & Networked \\
Media-rich & Lightweight \\
Distance learning & Situated learning \\
More formal & Informal \\
Simulated situation & Realistic situation \\
Hyper learning & Constructivist, situational, and collaborative \\
\hline
\end{tabular}




\subsection{Rationale of Mobile Learning}

It is very important to keep in mind that technology use in educational environments must be based on the dominant educational theories and approaches, (Patten, et. al., 2006), which is consequently applied to Mobile Learning as one form of technology use in education. For instance, learning, any learning, according to Behaviorism, takes place when a conditional correlation is established between a specific stimulus and a particular response, (Smith \& Ragan, 2005). For Mobile Learning, applications of Behaviorism are limited to its main principle, which is stimuli and responses. That is, students via Mobile Learning are provided by the learning content, the stimuli in this case, while the attached assignments, short tests, and feedback are the students' responses that follow. Cognitive Approach, on the other hand focuses on enabling the learner to reorganize his/her cognitive structures in a way that allows him to process and store newly acquired information that will be retained and recalled in future, (Good \& Brophy, 1990). Therefore, learners should be provided in advance with the learning materials and new knowledge. The availability of multimedia included in learners' mobile phones will help them process, organize, store, and recall the information they need anytime and anywhere. Situated Learning Theory hypothesises that learning is not merely a process of knowledge acquisition but primarily a social participation that seeks a solution for a problem, (Brown, et. al. 1989). Thus, an emphasis on creating real social contexts in which new knowledge can be delivered to learners provides them with a rich opportunity to simulate real life. By the use of social communication and networking means available on mobile phones such as discussions, groups, blogs, and learning at work environment can enhance and foster learning more than any other way.

Contextual Learning Theory blends modern developments of context-aware computing with teaching strategies that upholds situational and context-sensitive leanings, (De Jong, et. al. (2008). Mobile Learning, regarding this point can make learning contextual through certain practices based on mobile phones' technology that can bring real life in front of learners. A student can administer the learning context based learning content, browse, and retrieve it whenever he wishes. Location-Based Learning Theory tries to achieve what is known as Just-in-Time Learning connected to the physical location in which the learner resides. Taking into account this principle, Mobile Learning should account for the place of learning where the learner can be given a hand to acquire and learn not any knowledge but conceptual knowledge, (Johnson, et. al., 2009). According to the Cognitivist, learning is an active, constructive, cumulative, and self-directed process that is dependent on the mental activities of the learner, (Shuell, 1986). Thus, taking into consideration all these points discussed before, one can argue that Mobile Learning, because of the advanced technology embedded inside, can provide such mental, social, contextual, and spatial activities via micro learning all the day long and make the learning process more self-directed and regulated, Edge, et.al. (2011).

\subsection{Mobile Learning Theoretical Framework}

Today's mobile phones are unlike those ones that were common ten or fifteen years ago. They, each month get smarter and smarter. People of all kinds and mainly university students keep pace with all technological developments embedded in these mobiles. These students are more skilful in using them than parents or grandparents. Therefore, users of mobile phones can be directed to use them for educational, as well as, for communication purposes in a way that makes their learning easier and more enjoyable. Studies that have investigated how teachers can do so are many. In addition, studies that have checked whether mobile phones create an effect in students' academic achievement are numerous, too. For example, Dos (2014:1) showed that university students heavily used mobile phones. Students' academic achievement and metacognition awareness were developed and improved because of these mobile sets usage. While Jabbour (2013) revealed that 3G technology based-mobile phones when used for educational purposes affected students' attitudes. Students could enjoy themselves and try a positive learning experience. Their prospects of mobile phones' effectiveness had a positive impact on their learning outcomes. Bidaki, et.al. (2013:24) also concluded that the use of mobile learning method had quite significant impact on both students' academic achievement and self-regulation learning. Wang, et.al. (2009), on the other hand proved that mobile learning activities could engage students in the learning process much better than traditional ones. Students changed into active learners. They were behaviourally, intellectually and emotionally involved in their learning tasks. Furthermore, Hsu (3013) revealed that Mobile Assisted Language Learning (MALL) was a potential tool for constructivism in EFL learning.

On the contrary, other studies found that the use of Mobile Learning was not always effective. For instance, Kuznekoff \& Titsworth (2013) after examining the impact of using mobile phones on students' learning via video watching concluded that students who were using their mobile phones wrote down and recalled less information. The notes they took were few. Their achievement grades on the test were lower than peers who did not use their mobile phones actively. Chu (2012) also concluded that unexpectedly control group students' achievement was better than the achievement of students in the experimental group who were learning via mobile phones. No differences between 
students' extraneous cognitive load and germane cognitive load were found. While there was a significant difference between students' mental load degree in favour of the experimental group.

In conclusion, it is true that Mobile Learning devices definitely influence students' university life whether negatively or positively. However, once they are used in the right way, they can affect interaction patterns of teachers as well as students. They can enhance learning and teaching practice. Hence, instructional, curricular and organizational factors affecting the adoption of Mobile Learning in higher education institutions should be accounted for as long as we wish to use them effectively. Learners will be in danger and can be exposed to superficial learning if Mobile Learning experiences are not well designed. In addition, mobile devices might distract students from learning and deteriorate the quality of interaction between academics and students, Handal, et.al. (2013).

Therefore, the present study is aiming to determine the effect of a developed mobile-based educational website on students' academic achievement and conversational skills in English. For this sake, researchers of the present study carried out a thorough review to determine the main principles of some learning theories and to identify some of the merits of mobile phones' use in learners' daily life. As a result, a fourteen-lecture educational website that tried to combine principles of learning and characteristics of mobile phones was developed.

\subsection{Mobile Phone-based Educational Website}

To design and develop the mobile phone-based educational website, many Instructional Design Models related to E-learning were analyzed. Differences between E-learning and Mobile Learning were also accounted for. After that, a series of guiding steps through which the website design and production have gone, were concluded. Learners' characteristics, aims, and teaching activities were some of the factors that were taken into consideration. Besides, the web's content was split into smaller and shortened pieces to fit the mobile phones' monitors or screens. The general framework of Mobile Learning in the present study was based on two famous frameworks in this area. The first one is Motiwalla's (2007:586) Social Constructivism and Conversation theories-based Pull-Push Framework that indicates how users interact with mobile applications available via Internet. Push Technology, for instance represents the services provided to users without request such as advertisements and alerts that are provided by Blackboard. Push technology, on the opposite, refers to queries made by the user like, for example the discussions, groups, and blogs made available by Blackboard. The second is Koole's (2009:27) Frame Model for Mobile Education that is dependent upon Situational, Realistic, Contextual Learning, and Social Constructivism. Figure (1) illustrates this model.

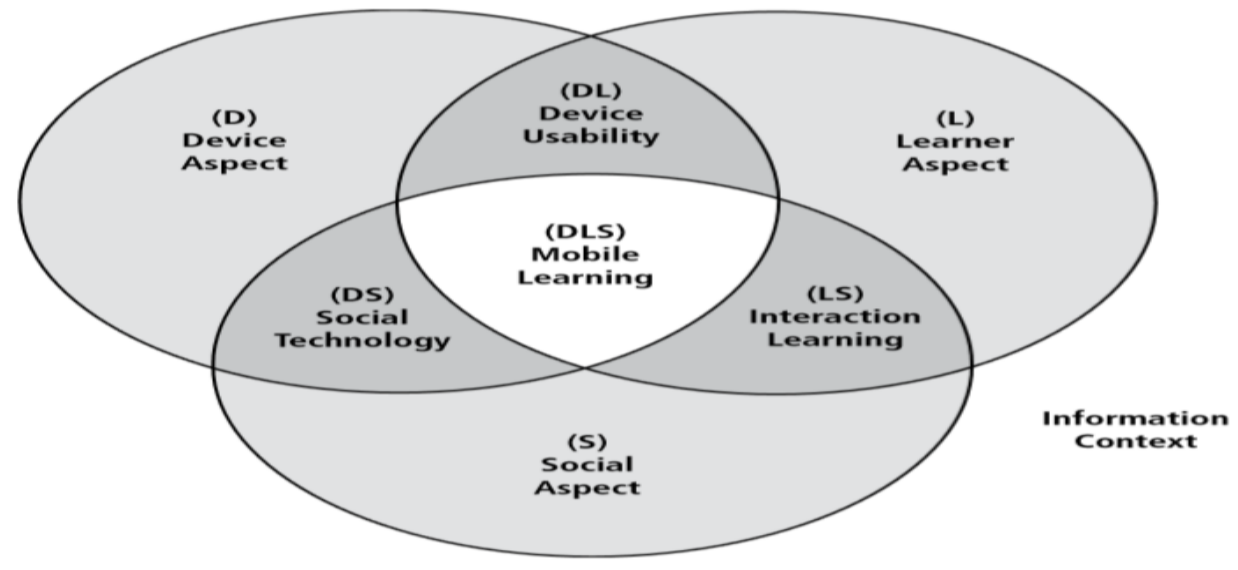

Figure 1. Koole's Frame Model

With reference to these three circles and three intersections as illustrated in figure (1), the first circle, "Device Aspect (D)", represents the physical and technical characteristics of mobile devices. Such characteristics are in congruence with those applications provided by E-Learning Deanship at Najran University via Blackboard System that accounts for Android and IOS operating systems. That is, the educational site provided via mobile phone is compatible with all mobile devices participants in the present study own. The second circle, "Learner Aspect (L)" stands for learners' emotional aspects and motivation regarding mobile use in education. Such emotional aspects and motivation toward contesting such an experiment were found high among participants through discussion with the researchers of the present study. "Social Aspect (S)" constitutes the third circle and represents social interactions and cooperation processes between the teacher and learners and/or among learners themselves. Much of these interactions such as discussions through forums; groups that facilitate cooperation among students and allow them to strengthen their 
virtual relations with peers; in addition to the blogs as open communication tools for students to share their ideas were provided by the proposed website delivered via blackboard-based Mobile Learning. Figure (1) also shows that there are three intersections among the three circles, namely DL, DS, and LS. The first intersection "Device Usability (DL)" cares about the common characteristics of aspects related to devices, on one hand, and aspects related to the learner, on the other hand, i.e. tasks dealing with knowledge and its storage. Thus, researchers' reliance on this point was based on the participants' background knowledge in the use of smart mobile phones encouraged by their high economic level and continual carefulness to follow up and keep the most recent devices. Furthermore, they all seemed to be highly capable of accessing, downloading, and saving information via their mobile sets. The second intersection "Social Technology (DS)" represents the social aspect of Mobile Learning, which is fulfilled through forums, groups, and available blogs for students to interact via their mobile phones. The last intersection "Interactive Learning (LS)" accounts for theories of learning and teaching. Figure (2) illustrates mobile phone-based website main screen, which was mainly developed for teaching students.

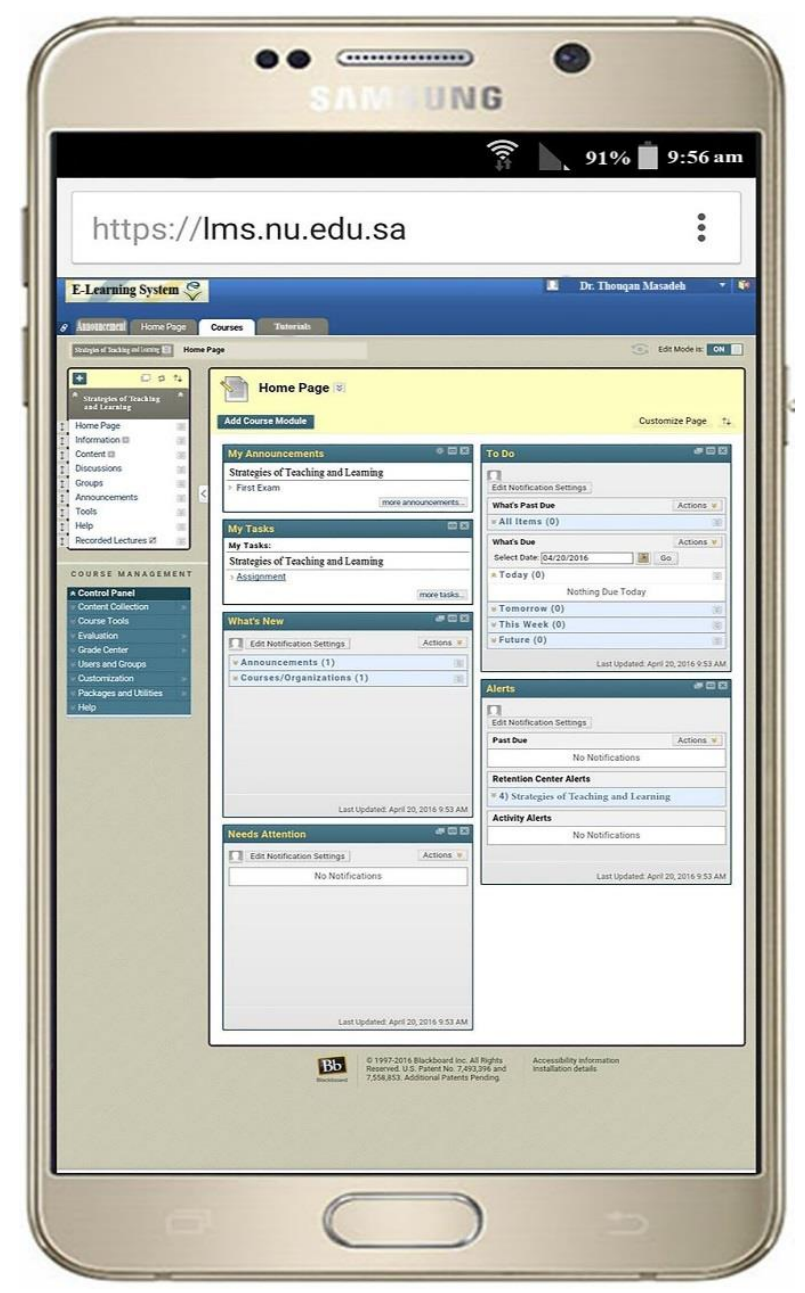

Figure 2. Mobile phone-based website main screen 
For the sake of completing building the mobile phone-based website, the teaching content of the "Strategies of Teaching and Learning" course was prepared, split into separate lectures using PowerPoint presentation, and uploaded to Blackboard System provided by Najran University. The course consisted of twelve lectures and could be accessed by clicking a link called 'Content" placed in the upper left corner of the main screen. In addition to the "Content" link, other links for discussions, groups, poster, and tools were added to encourage interaction among students themselves on one hand, and between students and instructor, on the other hand. Figure (3) illustrates mobile phone- based website content.

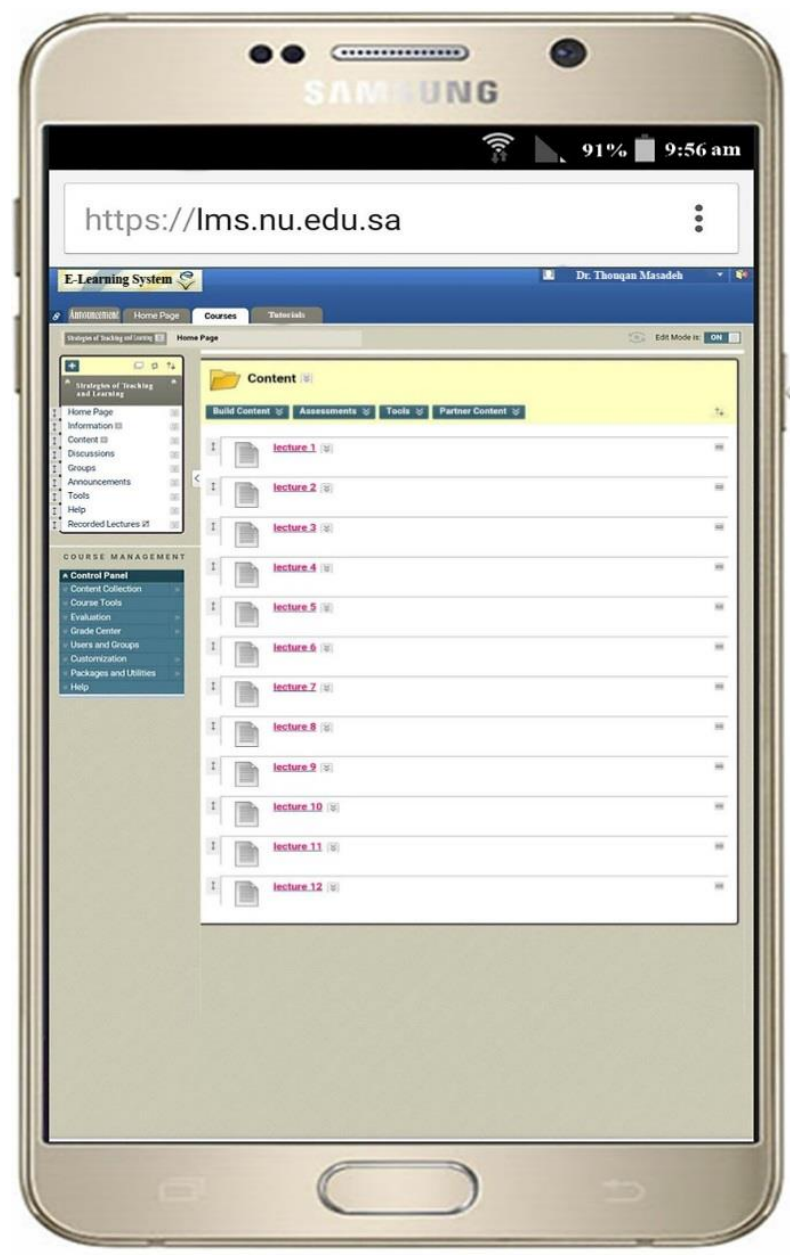

Figure 3. Mobile phone- based website content

\section{Method}

\subsection{Study design}

The study adopted the experimental approach to check whether the use of mobile phones (Mobile Learning) has an effect on students' academic achievement and conversational skills in English. An experimental design is usually used because it identifies easily the independent, dependent, and inconvenience variables. It also guides researchers how to implement the study sample randomization. In addition, it shows how to carry out the statistical aspects. Furthermore, it enables researchers to construct a relation between dependent and independent variables and excludes nuisance variables, (Kirk, 1995:1). Thus, an academic achievement pre and posttests of equivalent groups were employed for both groups. Besides, pre and post- participants' conversational skills ratings were implemented, too, as illustrated in table (2). 
Table 2. Pretest and posttest experiment design

\begin{tabular}{lccc}
\hline Group & Pre-test & Treatment & Post-test \\
\hline Experimental Group & $\mathrm{O}_{1}$ & $\mathrm{X}_{1}$ & $\mathrm{O}_{2}$ \\
Control Group & $\mathrm{O}_{1}$ & $\mathrm{X}_{2}$ & $\mathrm{O}_{2}$ \\
\hline
\end{tabular}

Note. $\mathrm{O}_{1}$ : Achievement/ conversation skills of pretest

$\mathrm{X}_{1}$ : Mobile learning Treatment

$\mathrm{O}_{2}$ : Achievement/ conversation skills of posttest

$\mathrm{X}_{2}$ : Traditional Treatment

\subsection{Participants}

Participants in the present study consisted of (50) students who were enrolled in two equal groups of "Strategies of Teaching and Learning" course in the first semester of the academic year 2015/2016. One of these groups was assigned as a control group, was taught by Face-to Face Learning while the other one represented the experimental group, and studied the course content via Mobile Learning. Both groups were subjected to the experiment for fourteen weeks.

\subsection{Study Instruments}

Two main instruments were developed for the sake of answering the questions of the present study, namely an academic achievement test and a scale for rating students' conversational skills in English.

\subsection{The Achievement Test}

Items in the achievement test were drafted based on the desired learning outcomes of "Strategies of Teaching and Learning" course in addition to participant students' academic level. The test consisted of three main parts. In the first part there were (5) questions of the essay type. The second part involved (15) multiple-choice statements whereas, the third one consisted of (10) True/False items. Twenty (25) points were assigned for the first part, i.e. (5) points for each essay question. Five (15) points were devoted to the second one, one point for each statement. Another (10) points were devoted to the third part, one point for each true/false statement. Thus, the total mark on the achievement test was (50) points. Prior to implementation, the test was piloted on (10) English majors at Najran University who were enrolled in "Practicum" course to determine the test needed time for completion, validity, and reliability. After calculating the time needed by those ten students, it was found that the approximate needed time was (90) minutes. Cronbach Alpha was then used to extract the test's reliability coefficient. Calculations showed that it was (0.86) indicating that results of such a test is fit for the study purpose and results will trustful.

\subsection{The Conversational skills Rating Scale (CSRS)}

The conversational skills rating scale was used for the sake of measuring the performance level of participant students' conversational skills. It was the same conversational skills rating scale (CSRS) developed by Spitzberg (1995:29), see Appendix (A). It consisted of two main parts. The first part consisted of (25) communicative behaviors that each student should display in conversation. The assessor was to assign a mark for each behavior beginning with (5 points) for excellent communicative behavior, (4 points) for good one, ( 3 points) if the communicative behavior was adequate, ( 2 points) and (1) point for fair and inadequate behaviors resectively. Therefore, each participant's total mark could be ranging between ( 25 up to 125 ). The other part was dealing with rating participant's overall performance regarding how good conversationalist; socially skilled; and competent, appropriate, and effective communicator he was. The assessor was also to evaluate each participant's conversational ability beginning with (1 point) if he was weak and going up to ( 7 points) if he was good. Thus, each participant could get (7 up to 35) points in the second part. Therefore, the total mark of both parts was (160) marks, (125) points for the first part and (35) points for the second part. For calculation considerations, the total mark of each student that was out of (160) was calculated to be out of (20) using the formula below.

\section{Student's final mark on CSRS $\times 20$}




\subsection{Participants' Homogeneity}

All students participating in the study sat for an achievement pre-test at the end of the first week of the course. Its aim was to make sure of their homogeneity regarding their background knowledge and academic achievement. At the beginning of the second week, the course instructor started assessing students" English conversational skills using Spitzberg's conversational rating scale as described before. Pre-assessment lasted for a week as the number was high. All participants' grades in the achievement test and conversational skills were documented and analyzed using ANOVA. Results regarding their homogeneity are illustrated in table (3) in accordance to the achievement test and table (4) with regard to CSRS.

Table 3. Variance between experimental and control groups' means regarding achievement pre-test

\begin{tabular}{lccccc}
\hline & Sum of Squares & DF & Mean of Square & F. ratio & Sig. \\
\hline Between Groups & 0.720 & 1 & 0.720 & 0.193 & 0.663 \\
Within Groups & 179.480 & 48 & 3.735 & & \\
Total & 180.000 & 49 & & &
\end{tabular}

Table (3) above shows that calculated F. ratio (0.193) was insignificant $(\alpha=0.05)$. In other words, there were no statistically significant differences between both groups in the academic pre-test achievement. That is students' academic achievement levels were homogeneous before the exposure to the treatment. Whereas, table (4) illustrates the participants' homogeneity in both groups with regard to their conversational skills before experimentation.

Table 4. Variance between experimental and control groups' means regarding conversation pre-assessment

\begin{tabular}{cccccc}
\hline & Sum of Squares & DF & Mean of Square & F. ratio & Sig. \\
\hline Between Groups & 0.500 & 1 & 0.500 & 0.278 & 0.609 \\
Within Groups & 86.480 & 48 & 1.802 & & \\
Total & 86.980 & 49 & & & \\
\hline
\end{tabular}

Table (4) above shows that calculated F. ratio $(0.278)$ was insignificant $(\alpha=0.05)$. In other words, there were no statistically significant differences between both groups in conversation pre-assessment. That is students were homogeneous with regard to their conversational skills mastery before the exposure to the treatment.

\section{Results}

Once the presentation of methodology finished and the main experiment ended, students' grades on the achievement test and CSRS were documented. T. test for two independent but equal samples was used to determine the significance of differences between the modified gain ratio of students' grades in both groups regarding their academic achievement and conversational skills.

\subsection{Results Related to Participant Students' Academic Achievement}

T. test was used to check whether there was a significant difference between the modified gain ratio of both groups' means on the academic achievement post-test. Table (5) shows these findings.

Table 5. The difference between participants' modified gain ratio regarding participants' achievement post-test

\begin{tabular}{lcccccc}
\hline Group & N & M & SD & Mean Difference & T. Ratio & Sig. \\
\hline Experimental Group & 25 & 34.3200 & 3.00998 & 7.1200 & 5.533 & 0.034 \\
Control Group & 25 & 27.2000 & 5.68624 & & & \\
\hline
\end{tabular}

As illustrated in table (5), T. value for the difference between participants' modified gain ratio in the control group (M$=$ $27.20)$ and the experimental one ( $M=34.32)$ regarding the academic achievement post-test was (5.533). In other words, the difference between both groups' mean scores was statistically significant and indicated that there was a significant difference $(\alpha=0.05)$ between the academic achievement of both participant groups in favor of the group whose mean score was higher, i.e. the experimental group that was taught via Mobile Learning.

\subsection{Results Related to Participant Students' Conversational Rating Scale CSRS}

To check whether there was a significant difference between the Modified Gain Ratio of both groups' means on Conversational Rating Scale post-evaluation, T. test was used. Table (6) reveals these findings. 
Table 6. The difference between participants' modified gain ratio regarding the Conversational Rating Scale

\begin{tabular}{lcccccc}
\hline Group & $\mathrm{N}$ & $\mathrm{M}$ & $\mathrm{SD}$ & Mean Difference & T. Ratio & Sig. \\
\hline Experimental Group & 25 & 16.1600 & 1.40475 & 3.2400 & 5.710 & 0.031 \\
Control Group & 25 & 12.9200 & 2.46509 & & &
\end{tabular}

Table (6) illustrates that the T. value for the difference between participants' modified gain ratio in the control group $(\mathrm{M}=12.92)$ and the experimental one $(\mathrm{M}=16.16)$ regarding the Conversational Rating Scale was (5.71). That is, the difference between both groups' mean scores was statistically significant and indicated that there was a significant difference $(\alpha=0.05)$ between the mastery of conversational skills of both participant groups in favor of the group who scored higher means, i.e. the experimental group that was taught via Mobile Learning.

\section{Discussion}

Analysis of the collected data revealed that Mobile learning was more effective than the use of traditional teaching methods in helping students enrolled in "Strategies of Teaching and Learning" course to achieve better and develop their English language conversational skills. The modified gain ratio of students' mean scores was apparent in improving their academic achievement in addition to their conversational skills in English. In other words, students' understanding and comprehension of the course's learning content provided via Mobile Learning was much better than their peers' understanding and comprehension of the same content through the use of traditional ways of teaching, i.e. Face-to-Face learning. Such success and effect can be referred to a set of elements related to mobile phones' characteristics and technology. One of these factors is the fact that mobile phones could make learning easier and fast without time and place constraints. On the other part, the mobility that Mobile Learning depends upon could allow students to easily interact and discuss the learning topics with colleagues or instructor anytime and anywhere. Their leisure was effectively used and changed into precious time full of useful activities. Besides, mobile learning contributed to the support of the interactive characteristics of learning and teaching environment making students' role more effective through the active interaction with the teaching/learning materials via mobile sets. In addition, it can be said that students' achievement and conversational skills were enhanced because of the privacy offered by Mobile Learning, which could support student's private learning opportunities by the independent access of learning materials and information and so it was easier for the instructor to identify individual differences among them. Furthermore, Mobile Learning spontaneity and contextualization could make the teaching process student-centered going along with the philosophy of Constructivist Approach resulting in making them willingly able to access the teaching content and interact with it. Another important element in the success of students learning via Mobile Learning was the various opportunities and occasions through which learners were allowed to access and make use of the large amount of information available on Internet for the sake of educational aims and assignments.

Findings of the present study regarding the effect of Mobile Learning on the development of Students' achievement and conversational skills corroborates those findings concluded by Dos (2014) regarding the development of students' achievement and metacognition as a result of Mobile Learning. They also assert the findings of Jabbour (2013) with regard to students' positive attitudes towards Mobile Learning, the enjoyment they had, and the positive learning experience they went through. Findings of the present study also approximately match those results concluded by Bidaki, et.al. (2013) in accordance to students' achievement improvement and self-regulation. To have higher achievement grades and be a good language user when communicating with a teacher or colleagues means that the teaching content and the way used for teaching were both effective. Results of the present study proved that by using Mobile Learning, students were more successful in their academic achievement and conversation. Therefore, an agreement can be seen between the results of the present study and the findings of Wang, et.al. (2009) in relation to the ability of Mobile Learning to convert learners from passive into active ones who were behaviorally, intellectually, and emotionally involved in their learning tasks.

However, findings of the present study do not go along with or support the findings of some studies, i.e. Kuznekoff \& Titsworth (2013) and Chu (2012). Which found that Mobile Learning was not an effective learning style and consequently could not affect learners" academic achievement. Nevertheless, such a disagreement does not negate or emphasize the effectiveness of Mobile Learning in improving learners' achievement. Each study has its own circumstances related to teachers, students, and ways of assessment ...etc.

\section{Conclusion}

The main aim of the present study was to identify the effect of Mobile Learning on the development of students' academic achievement and conversational skills. Results were quite positive and encouraging for students and teachers 
because of Mobile Learning ability to wipe out time and place difficulties in learning. Students can access their lessons and deliver their assignments via their mobile sets whenever and wherever. Teachers, on the other hand, can upload the teaching material, assign the roles, determine discussions and receive students' assignment electronically. However, educationists should understand that nothing of the mentioned above could take place unless all learning activities are well designed and carefully implemented.

\section{Recommendations for Future Research}

In light of the findings of the present study, educationists and educators are recommended to:

1. use Mobile Learning in all similar educational contexts,

2. benefit from Mobile Learning when developing the conversational skills of English language majors at Najran University.

3. gradually use Mobile Learning in other colleges to replace traditional learning methods,

4. inform interested people of the importance of Mobile Learning and how it can be used to help students exploit their leisure and change it into productive activity, and

5. train faculty members on how to produce teaching materials and prepare their courses that fit Mobile Learning through professional development training sessions.

\section{References}

Behera, S. K. (2013). E- and M-learning: A Comparative Study. International Journal on New Trends in Education and Their Implications, 4(3), 65 - $78 . \quad$ Retrieved from http://www.ijonte.org/FileUpload/ks63207/File/08.behera.pdf

Bidaki, M. Z.; Naderi, F.; \& Ayati, M. (2013), Effects of Mobile Learning on Paramedical Students' Academic Achievement and Self-regulation. Future of Medical education Journal, 3(3), 24-28. Retrieved from http://fmej.mums.ac.ir/article_1524_0.html

Brown, J. S., Collins, A., \& Duguid, P. (1989). Situated Cognition and the Culture of Learning. Educational Researcher, 18(1), 32-42. http://dx.doi.org/10.3102/0013189X018001032

Chu, H. C. (2014). Potential Negative Effects of Mobile Learning on Students' Learning Achievement and Cognitive Load-A Format Assessment Perspective. Educational Technology \& Society, 17 (1), 332-344. Retrieved from http://www.ifets.info/journals/17_1/28.pdf

De Jong, T., Specht, M. \& Koper, R. (2008). A Reference Model for Mobile Social Software for Learning. International Journal of Continuing Engineering and Lifelong Learning, 18(1), 118-138. http://dx.doi.org/10.1504/IJCEELL.2008.016079

Dos, B. (2014). The Relationship Between Mobile Phone Use, Metacognitive Awareness and Academic Achievement. European Journal of Educational research, 3(4), 192-200. Retrieved from http://files.eric.ed.gov/fulltext/EJ1085990.pdf

Edge, D.; Searle, E.; Chiu, K.; Zhao, J.; \& Landay, J. (2011). Micro Mandarin: Mobile Language Learning in Context, CHI '11 Proceedings of the SIGCHI Conference on Human Factors in Computing Systems Pages 3169-3178. Retrieved from http://dl.acm.org/citation.cfm?id=1979413

El- Hussein, M. O. M., \& Cronje, J. C. (2010). Defining Mobile Learning in the Higher Education Landscape. Educational Technology \& Society, 13(3), 12-21. Retrieved from http://www.ifets.info/journals/13_3/3.pdf

Good, T. L., Brophy, J. E. (1990). Educational psychology: A Realistic Approach, (4t ${ }^{\mathrm{h}}$ edition), White Plains, NY: Longman.

Handal, B.; MacNish, J.; \& Petocz, P. (2013). Adopting Mobile Learning in Tertiary Environments: Instructional, Curricular and Organizational Matters. Educ. Sci. 3, 359-374. http://dx.doi.org/10.3390/educsci3040359

Hsu, L. (2013). English as a foreign language learners' perception of mobile assisted language learning: a cross-national study. Computer Assisted Language Learning, 26(3), 197-213. http://dx.doi.org/10.1080/09588221.2011.649485

Jabbour, K. K. (2013). An Analysis of the Effect of Mobile Learning on Lebanese Higher Education. Bulgarian Journal of Science and Education Policy (BJSEP), 7(2), 280-301. Retrieved from http://bjsep.org/getfile.php?id=145 
Johnson, D. W. (2009). Reaching out: Interpersonal effectiveness and self- actualization ( $10_{\text {th }}$ edition.), Boston: Allyn \& Bacon.

Kim, D., Rueckert, D., Kim, D. J. \& Seo, D. (2013). Student' Perceptions and Experiences of Mobile learning. Language Learning \& Technology, 17(3), pp. 52-73. Retrieved from http://ltt.msu.edu/issues/october2013/kimetal.pdf

Kirk, R. E. (1995). Experimental Design: Procedures for the Behavioural Sciences ( $4^{\text {th }}$ edition). SAGE Publication: USA.

Retrieved from http://www.amazon.com/Experimental-Design-Procedures-Behavioral-Sciences/dp/1412974453

Koole, M. (2009a). Chapter 2: A Model for Framing Mobile Learning. In M. Ally (Ed.), Mobile Learning: Transforming the Delivery of Education and Training (Vol. 1, pp. 25-47). Edmonton, Alberta: AU Press. Retrieved from http://www.aupress.ca/books/120155/ebook/02_Mohamed_Ally_2009-Article2.pdf

Korucu, A. T. \& Alkan, A. (2011). Differences between M-Learning (Mobile Learning) and E-Learning, Basic Terminology and Usage of M-Learning in Education. Procedia Social and Behavioural Sciences, 19, 1925:1930. http://dx.doi.org/10.1016/j.sbspro.2011.04.029

Kuznekoff, J. \& Titsworth, S. (2013). The Impact of Mobile Phone Usage on Student Learning. Communication Education, 62(3), 223-252. http://dx.doi.org/10.1080/03634523.2013.767917

Lan, Y. F., \& Huang, S.-M. (2012). Using Mobile Learning to Improve the Reflection: A Case Study of Traffic Violation. Educational Technology \& Society, 15(2), 179-193. Retrieved from http://www.ifets.info/journals/15_2/16.pdf

Laouris Y. \& Eteokleous. (2005). We Need an Educationally Relevant Definition of Mobile Learning. Proc. $4^{\text {th }}$ World Conference on Mobile Learning, mLearn 2005, Oct 25 - 28, Cape Town, South Africa. Retrieved from http://www.mlearn.org.za/CD/papers/Laouris\%20\&\%20Eteokleous.pdf

Little, B. (2012). Effective and Efficient Mobile Learning: Issues and Tips for Developers. Industrial and Commercial Training, 44(7), 402-407. http://dx.doi.org/10.1108/00197851211267983

López, G. J. L, Royo, T. M., Laborda, J. G., \& Calvo, F. G. (2009). Methods of Adapting Digital Content for the Learning Process via Mobile Devices. Procedia Social and Behavioural Sciences, 1(1), 2673-2677. http://dx.doi.org/10.1016/j.sbspro.2009.01.472

Motiwalla, L. F. (2007). Mobile Learning: A Framework and Evaluation. Computers \& Education 49, 581-596. http://dx.doi.org/10.1016/j.compedu.2005.10.011

Patten, B., Sanchez, A. I., \& Tangney, B. (2006). Designing Collaborative, Constructionist and Contextual Applications for Handheld Devices: Virtual Learning. Computers and Education, 46, 294-308. http://dx.doi.org/10.1016/j.compedu.2005.11.011

Shuell, T. (1986). Cognitive Conceptions of Learning. Review of Educational Research 56, 411-436. Retrieved from http://rer.sagepub.com/content/56/4/411.short

Smith, P. L. \& Ragan, T. J. (2005). Instructional Design, (3 $3_{\mathrm{rd}}$ Edition), Hoboken, NJ: Wiley.

Spitzberg, b. H., (1995). CSRS The Conversational Skills Rating Scale: An Instructional Assessment of Interpersonal Competence, San Diego State University: NCA Diagnostic Series. Retrieved from https://www.natcom.org/uploadedFiles/Teaching_and_Learning/Assessment_Resources/PDF-Conversation_Skill s_Rating_Scale_2ndEd.pdf

UNISCO. (2013). Policy Guidelines for Mobile Learning, Kraut, R (editor), France: The United Nations Educational, Scientific and Cultural Organization (UNISCO), Retrieved from http://unesdoc.unesco.org/images/0021/002196/219641e.pdf

Wang, M.; Shen, R.; Novak, D.; \& Pan, X., (2009). The Impact of Mobile Learning on Students' Learning Behaviours and Performance: Report from a large blended classroom. British Journal of Educational Technology (BJET), 40 (4), 673-695. http://dx.doi.org/10.1111/j.1467-8535.2008.00846.x

West, D. M. (2013). Mobile Learning: Transforming Education, Engaging Students, and Improving Outcomes, Centre for Technology Innovation at Brooking. Retrieved from http://www.brookings.edu/ /media/research/files/papers/2013/09/17-mobile-learning-education-engaging-student s-west/brookingsmobilelearning_final.pdf 


\section{Appendix (A)}

\begin{tabular}{|c|c|c|c|c|c|c|c|c|c|c|c|c|c|}
\hline \multicolumn{14}{|c|}{ CONVERSATIONAL SKILLS RATING SCALE (Observer Rating of Conversant Form) } \\
\hline \multicolumn{10}{|c|}{ Examiner Name: } & \multicolumn{4}{|c|}{ Conversant name: } \\
\hline \multicolumn{10}{|l|}{ Date: } & \multicolumn{4}{|c|}{ Course: } \\
\hline \multicolumn{14}{|c|}{$\begin{array}{c}\text { Rate how skilfully this student used, or did not use, the following communicative behaviours in the } \\
\text { conversation. }\end{array}$} \\
\hline \multicolumn{3}{|c|}{ 1= Inadequate } & \multicolumn{11}{|c|}{ (use is awkward, disruptive, or results in a negative impression of communicative skills) } \\
\hline \multicolumn{3}{|c|}{$2=$ Fair } & \multicolumn{11}{|c|}{ (occasionally awkward or disruptive, occasionally adequate) } \\
\hline \multicolumn{3}{|c|}{$3=$ Adequate } & \multicolumn{11}{|c|}{$\begin{array}{l}\text { (Sufficient but neither noticeable nor excellent. Produces neit } \\
\text { impression) }\end{array}$} \\
\hline \multicolumn{3}{|c|}{ 4= Good } & \multicolumn{11}{|c|}{ (use was better than adequate but not outstanding) } \\
\hline \multicolumn{3}{|c|}{ 5= Excellent } & \multirow{2}{*}{\multicolumn{11}{|c|}{$\begin{array}{l}\text { (use is smooth, controlled, results in positive impression of communicative skills) } \\
\text { Circle the single most accurate response for each behaviour: }\end{array}$}} \\
\hline \multirow{2}{*}{\multicolumn{14}{|c|}{$\begin{array}{ll}\text { Circle the single most accurate response for each behaviour: } \\
\text { Mark obtained }\end{array}$}} \\
\hline & & & & & & & & & & & & & \\
\hline 1. & 1 & 2 & 3 & 4 & 5 & \multicolumn{8}{|c|}{ Speaking rate (neither too slow nor too fast) } \\
\hline 2. & 1 & 2 & 3 & 4 & 5 & \multicolumn{8}{|c|}{ Speaking fluency (pauses, silences, “uh”, etc.) } \\
\hline 3. & 1 & 2 & 3 & 4 & 5 & \multicolumn{8}{|c|}{ Vocal confidence (neither too tense/nervous nor overly confident sounding) } \\
\hline 4. & 1 & 2 & 3 & 4 & 5 & \multicolumn{8}{|c|}{ Articulation (clarity of pronunciation and linguistic expression) } \\
\hline 5. & 1 & 2 & 3 & 4 & 5 & Vocal variet & (neitl & er ov & rly & ono & ne $n$ & $\mathrm{rd}$ & matic voice) \\
\hline 6. & 1 & 2 & 3 & 4 & 5 & Volume (nei & er to & loud & nor & o sc & & & \\
\hline 7. & 1 & 2 & 3 & 4 & 5 & Posture (neit & r toc & close & $1 / f \mathrm{fo}$ & nal n & r tor & ope & /informal) \\
\hline 8. & 1 & 2 & 3 & 4 & 5 & Lean toward & artne & (nei & er t & o for & vard & or & oo far back) \\
\hline 9. & 1 & 2 & 3 & 4 & 5 & Shaking or $n$ & vous & witc & es ( & ren't & notic & $\overline{a b l}$ & or distracting) \\
\hline 10. & 1 & 2 & 3 & 4 & 5 & Unmotivated & nove & nents & tap & $\operatorname{lng} f$ & et, fi & ger & , hair twirling, etc.) \\
\hline 11. & 1 & 2 & 3 & 4 & 5 & Facial expres & ivene & $\mathrm{s}(\mathrm{n}$ & ther & blank & nor & $\mathrm{xag}$ & erated) \\
\hline 12. & 1 & 2 & 3 & 4 & 5 & Nodding of $h$ & $\mathrm{ad}$ in & espc & ise & part & er st & tem & nts \\
\hline 13. & 1 & 2 & 3 & 4 & 5 & Use of gestur & s to $e$ & npha & ize & hat & beil & g sa & \\
\hline 14. & 1 & 2 & 3 & 4 & 5 & Use of humo & and & br st & ies & & & & \\
\hline 15. & 1 & 2 & 3 & 4 & 5 & Smiling and// & laus & ing & & & & & \\
\hline 16. & 1 & 2 & 3 & 4 & 5 & Use of eye cc & tact & & & & & & \\
\hline 17. & 1 & 2 & 3 & 4 & 5 & Asking of qu & stion & & & & & & \\
\hline 18. & 1 & 2 & 3 & 4 & 5 & Speaking abc & it par & $\operatorname{ner}($ & ivol & eme & of 1 & 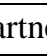 & r as a topic of conversation) \\
\hline 19. & 1 & 2 & 3 & 4 & 5 & Speaking abc & it sel & (neit & er t & $\mathrm{mu}$ & h no & too & little) \\
\hline 20. & 1 & 2 & 3 & 4 & 5 & Encouragem & ts or & agre & nen & (en & oura & eme & t of partner to talk) \\
\hline 21. & 1 & 2 & 3 & 4 & 5 & Personal opir & on ex & oress & on ( & eithe & too & assi & e nor aggressive) \\
\hline 22. & 1 & 2 & 3 & 4 & 5 & Initiation of 1 & $\mathrm{w}$ to & & & & & & \\
\hline 23. & 1 & 2 & 3 & 4 & 5 & Maintenance & f top & cs an & fol & $\mathrm{w}-\mathrm{u}$ & con & men & \\
\hline 24. & 1 & 2 & 3 & 4 & 5 & Interruption & part & er $\mathrm{sp}$ & akil & tur & & & \\
\hline 25. & 1 & 2 & 3 & 4 & 5 & Use of time $s$ & eakir & rel & ive & par & & & \\
\hline & & & & & & lext five item & rat & this & ers & n's 0 & eral & & ormance: \\
\hline Poor cc & onv & satic & halis & & & \begin{tabular}{l|l} 
& 1
\end{tabular} & 2 & 3 & 4 & 5 & 6 & 7 & Good conversationalist \\
\hline Sociall & y ur & kille & & & & 1 & 2 & 3 & 4 & 5 & 6 & 7 & Socially skilled \\
\hline Incomp & pete & t cor & mun & cator & & 1 & 2 & 3 & 4 & 5 & 6 & 7 & Competent communicator \\
\hline Inappr & opri & e co & $\mathrm{nmu}$ & icato & & 1 & 2 & 3 & 4 & 5 & 6 & 7 & Appropriate communicator \\
\hline Ineffec & tive & coms & Iunic & & & 1 & 2 & 3 & 4 & 5 & 6 & 7 & Effective communicator \\
\hline
\end{tabular}

